$\xi=\square$

\title{
Growth of spray pyrolysis deposited copper oxide thin film
}

\author{
Sachin H. Dhawankar ${ }^{1 *}$, Avish K Patil ${ }^{2}$, B M. Suryavanshi ${ }^{2}$, Manish P Tirpude ${ }^{3}$ \\ ${ }^{1}$ Department of Physics, Chhatrapati Shivaji Institute of Technology, Durg - 491001 (C.G), India \\ ${ }^{2}$ Department of Physics, Govt. Institute of science, Nagpur-440001(M.S), India \\ ${ }^{3}$ Department of Physics, E. S. Andrades of Science, Vasai, Dist Palghar- 401202 (M.S) India \\ *Corresponding author E-mail: dhawankar.sachin@ rediffmail.com
}

\begin{abstract}
Copper oxide thin film is deposited on the glass slide using aqueous solution of copper chloride and hydrogen peroxide by using spray pyrolysis deposition technique. The deposited $\mathrm{CuO}$ thin film is adherence and homogeneity with high transparency in visible region. Investigation of $\mathrm{CuO}$ thin film for physical properties is done. By using UV -Visible Spectrophotometer optical properties like absorption, transmission, energy band gap, Absorption coefficient and extinction coefficient in the visible region $(380-1000 \mathrm{~nm})$ are studied. The X-ray diffraction of $\mathrm{CuO}$ thin film is polycrystalline in nature with monoclinic crystal structure. The resistivity of Cuo thin film is studied using four probe methods.
\end{abstract}

Keywords: Cuo Thin Film; XRD; Electrical Properties; Absorption Coefficient and Extinction Coefficient.

\section{Introduction}

Copper oxide belongs to I - VI compound of semiconductor material [1]. $\mathrm{CuO}$ is a p-type semiconductor material with band gap of $1.21-1.51 \mathrm{eV}$ having monoclinic crystal structure [2]. $\mathrm{Cu}_{2} \mathrm{O}$ thin film exhibited good electrical and optical [3]. Copper oxide thin films are used in solar cell application [4], thin film batteries [5], gas sensing [6] etc. various method are used to deposition copper oxide thin film like sol-gel [7], magnetron sputtering [8],successive ionic layer adsorption and reaction [1], spray pyrolysis [9-10], Spin coating[11] etc.

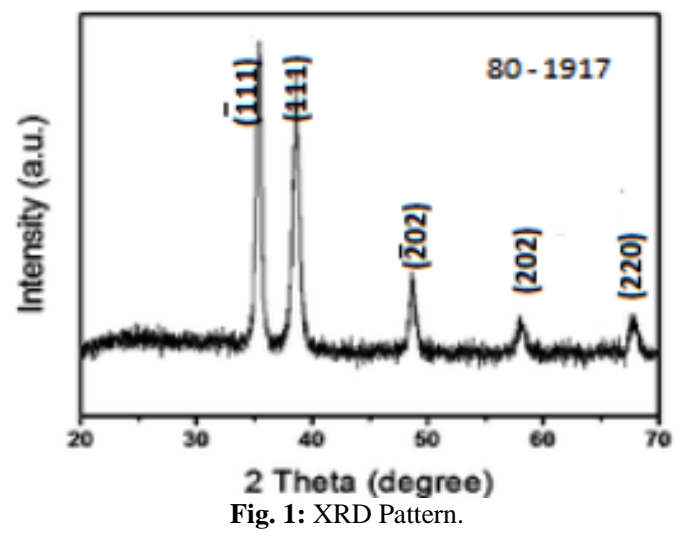

In the present work copper oxide thin film is deposited using spray pyrolysis method. Optical, Structural and electrical properties of deposited $\mathrm{CuO}$ thin film are studied by using UV-VIS spectrometer, $\mathrm{X}$ - ray diffraction pattern and electrical resistivity by four probe method. Absorption spectrum of $\mathrm{CuO}$ thin film is carried out in optical range $(380-1000 \mathrm{~nm})$. The energy band gap of thin film is observer at $1.5 \mathrm{e} \mathrm{V}$.

\section{Experimental detail}

Glass slide used deposition of $\mathrm{CuO}$ thin film is cleaned in conc. Nitrate acid, alcohol, double distilled water and ultrasonic cleaner for several times to remove the impurities on the surface. To calculate the thickness of deposited $\mathrm{CuO}$ thin film the glass slide is weigh before and after deposition using electron unipan microbalance of accuracy $10^{-4} \mathrm{gm}$. Copper chloride of $0.1 \mathrm{~N}$ is prepared in double distilled water and Conc. hydrogen peroxide of $3.5 \mathrm{cc}$ was mixed to formed aqueous and clear solution of copper oxide precursor in spray. Cleaned glass slide was arranged on metal plate with heating coil at $350^{\circ} \mathrm{C}$.After deposition glass slide was allow to cool down at room temperature.

Deposited $\mathrm{CuO}$ thin film is used to study structural, optical, and electrical properties [12-16]. Structural studied of $\mathrm{CuO}$ thin film was carried out on $\mathrm{X}$ - ray diffractometer using $\mathrm{Cu}-\mathrm{k} \alpha$ radiation. Optical absorption \& percentage transmission were measured by UV - VIS Spectrophotometer Elco (SL- 159) in the wavelength range $380-1000 \mathrm{~nm}$.

\section{Result and discussion}

\subsection{Structural observation of the $\mathrm{CuO}$ thin film}

Fig. 1 show X-ray diffraction pattern to find the structural information of $\mathrm{CuO}$ thin film. The nature of $\mathrm{CuO}$ thin film is polycrystalline with monoclinic crystal structure. The $2 \theta$ angle peaks are shown at $35.504^{0}, 38.735^{\circ}, 48.660^{\circ}, 58.372^{0}, 68.057^{\circ}$ with oriented (-111) (111) (-202) (202) (220) direction and agreement with Card Number $80-1917$

\subsection{Optical properties of $\mathrm{CuO}$ thin film}


Optical absorption spectra of thin film were studied on ELCO SL159 Spectrophotometer in optical range of 380 $1000 \mathrm{~nm}$.Absorbance (A) and \% transmission variation with wavelength are shown in Fig. 2 and Fig. 3. The band gap of the $\mathrm{CuO}$ thin film is calculated by equation no.1 of stern [11-14].

$(\alpha . h v)^{2}=K(h v-E g)^{n}$

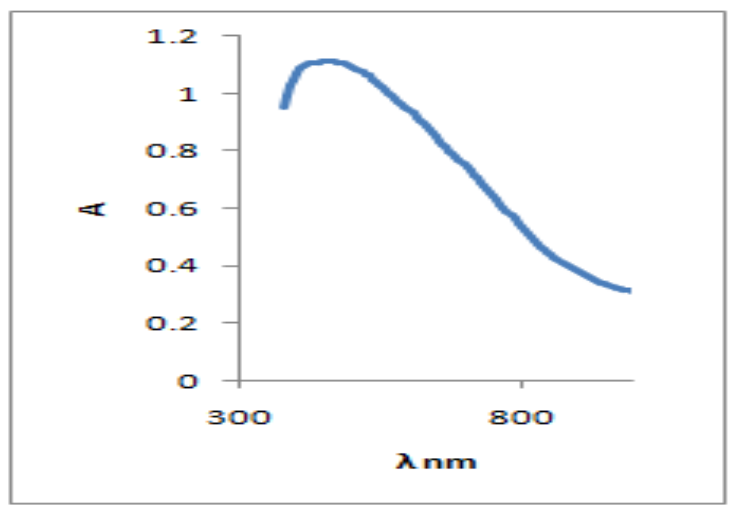

Fig. 2: Absorption Spectra.

Where $v=$ the frequency of radiation, $\mathrm{h}=$ Planck's constant, $\mathrm{K}=$ constant, $\mathrm{n}=1$ for direct band gap material. Fig 6 shows the variation of absorption coefficient with linear function of frequency. Band gap energy of grown $\mathrm{CuO}$ film is studied and observer. The thickness of thin film is calculated by using weight different density method which is most convenient method to calculate the thickness of thin film [16].The absorption coefficient $(\alpha)$, extinction coefficient $(\mathrm{K})$ of $\mathrm{CdS}$ thin films are studied and shown in Fig. 4, 5 .

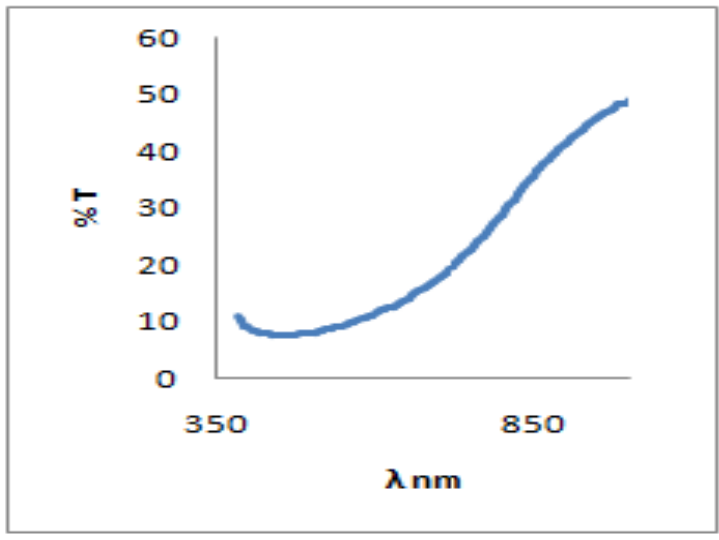

Fig. 3: Transmission Spectra.

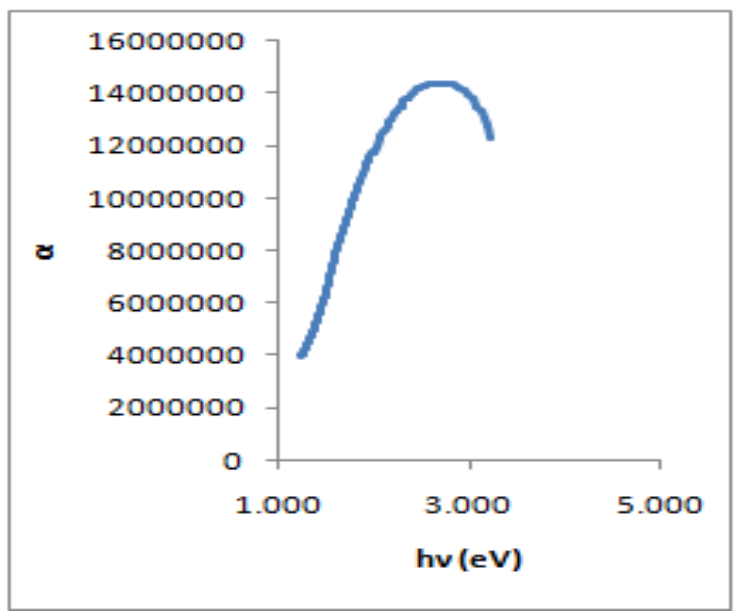

Fig. 4: Absorption Coefficient.

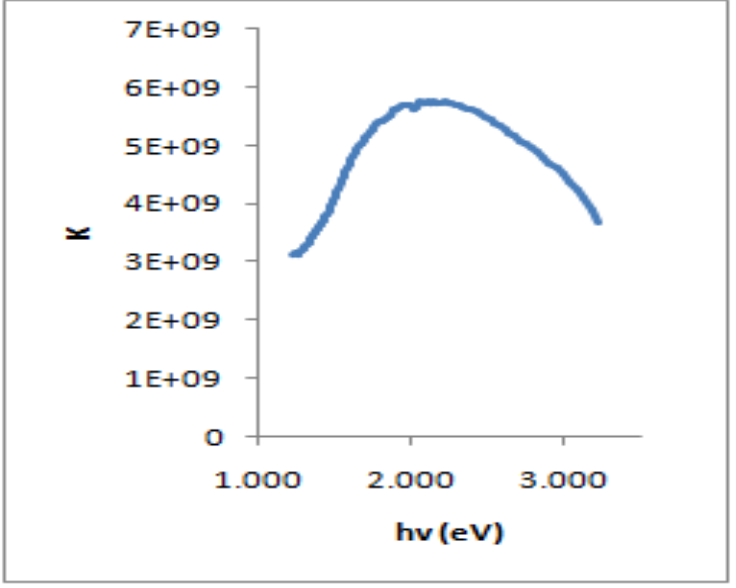

Fig. 5: Extinction Coefficient

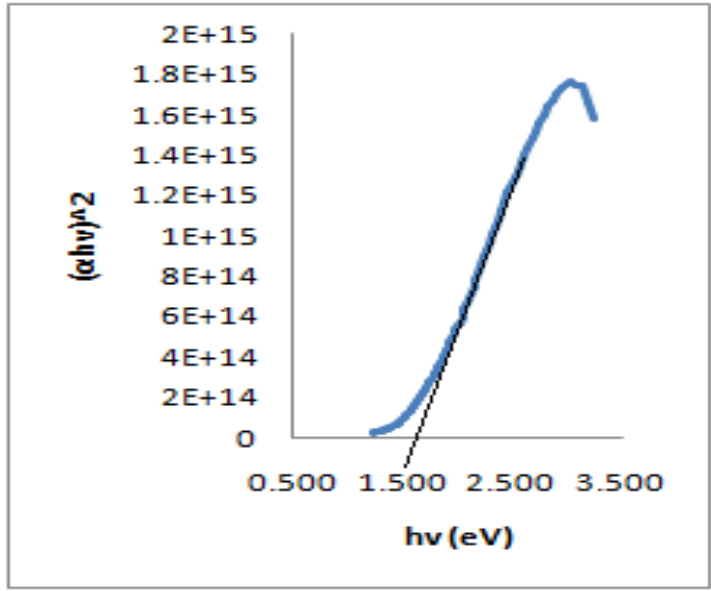

Fig. 6: Optical Energy Gap.

\subsection{Electrical studied}

Electrical studied of $\mathrm{CuO}$ thin film are carried out using four probe methods. Due to the combination of current and voltage probe correction factor is applied to determine resistivity of the thin film. Fig. 7 and Fig. 8 show the resistivity and conductivity as a function of temperature. Electrical conductivity as a function of inverse of temperature for thin films is show in Fig.9. Resistivity of the thin film is decreases with the increases in temperature and conductivity is increased with increase in temperature.

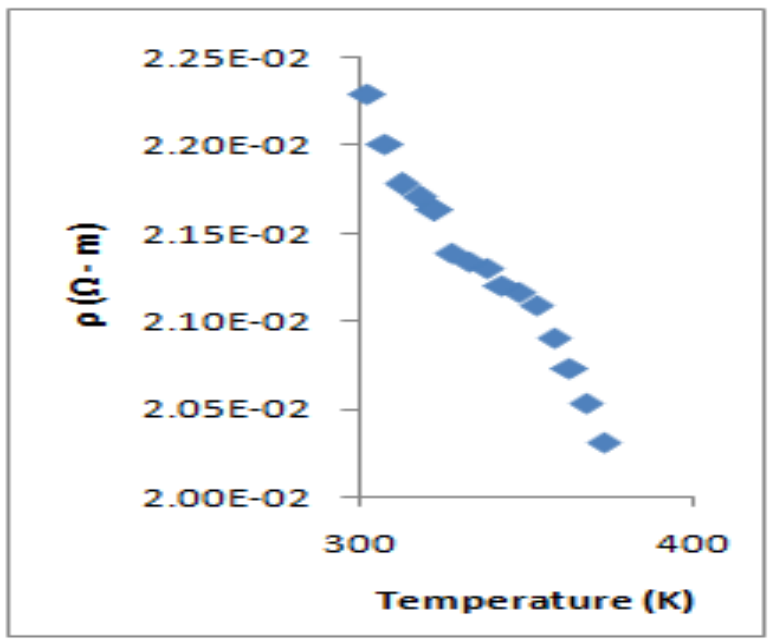

Fig. 7: Electrical Resistivity. 


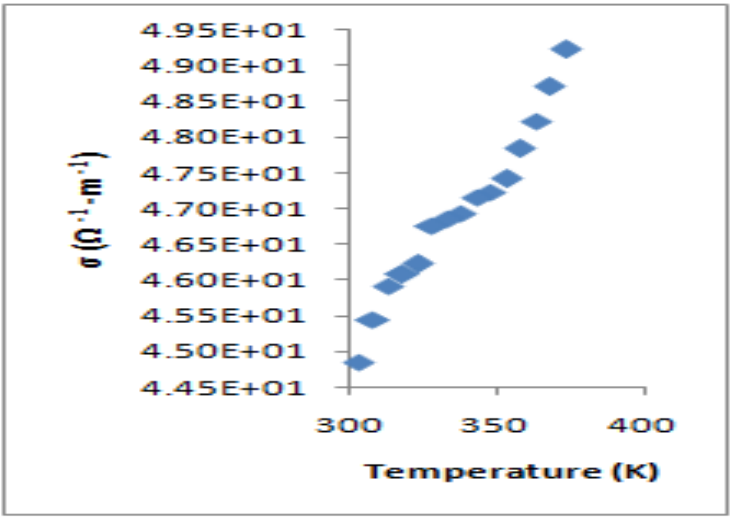

Fig. 8: Electrical Conductivity.

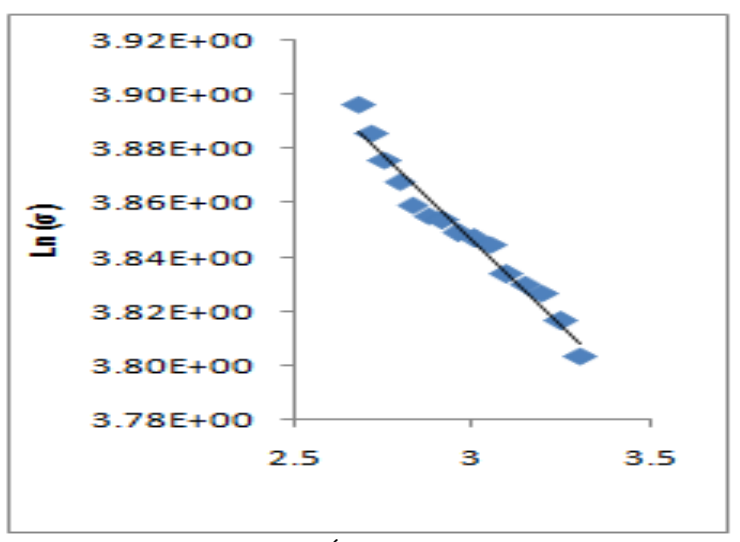

Fig. 9: Ln (Ó) Vs. 1000/T (K $)$.

\section{Conclusion}

By using spray pyrolysis technique $\mathrm{CuO}$ thin film are successfully deposited at $350^{\circ} \mathrm{C}$. The structural properties were studied by XRD pattern which examine thin film is polycrystalline in nature. Optical studied of $\mathrm{CuO}$ thin film are carried out by using UV Visible Spectrophotometer in the visible region $(380-1000 \mathrm{~nm})$. Different variation of optical properties shows that $\mathrm{CuO}$ thin film is suitable for application of solar devices. Absorption coefficient $(\alpha)$, extinction coefficient $(\mathrm{K})$ of thin films is studied. The direct band gap of thin films is obtained at $\mathrm{Eg}=(1.5 \mathrm{eV})$. Variation of resistivity, conductivity shows that deposited material is semiconducting and charge carrying material

\section{References}

[1] H.M.Pathan, C.D.Lokande Deposition of metal chalcogenide thin films by successive ionic layer absorption and reaction (SILAR) method Bull. Mater. Sci. 27, P $85 \quad-111,2004$ https://doi.org/10.1007/BF02708491.

[2] Balamurunga B and Mehta B R 2001 Thin Solid Films 39690. https://doi.org/10.1016/S0040-6090(01)01216-0.

[3] G Papadimitropoulos, N Vourdas, V Em Vamvakas, D Davazoglou; J. Phys.: Conference Series 10 (2005) 182-185] https://doi.org/10.1088/1742-6596/10/1/045.

[4] K, Borgohain, S, Mahamuni. J Mater. Res 171219

[5] E.A. Souza, R. Landers, L.P. Cardoso, Tersio G.S. Cruz, M.H Tabacniks, A. Gorenstein; J. Power Sources 155 (2006) 358-363 https://doi.org/10.1016/j.jpowsour.2005.04.014

[6] Liu J, Huang X, Gang Ye, Liu W, Jiao Z, Chao W, Zhou Z and Yu Z. Sensors (2003) 2 110. https://doi.org/10.3390/s30500110.

[7] Armelao L, Barreca D, Beriapelle M, Borraro G, Sada C and Tondello E, mater, Res. Soc, Symp. Pro. (2003) 737

[8] A.A. Ogwu, T.H. Darma, E. Bouquerel; J. Achievements Materi. Manufact. Engg. 24 (2007) 172-177

[9] V. Saravanakannan, T. Radhakrishnan, Structural, Electrical and Optical Characterization of Cuo ThinFilms Prepared by Spray Pyrolysis Technique International Journal of ChemTech Research,Vol.6, pp 306-310, Jan-March 2014
[10] Vignesh Saravanan, Prabakaran Shankar, Ganesh Kumar Mani,John Bosco Balaguru Rayappan, Growth and characterization of spray pyrolysis deposited copper oxide thin films: Influence of substrate and annealing temperatures Journal of Analytical and Applied $\begin{array}{llll}\text { Pyrolysis } & 111 & \text { (2015) } & 272-277\end{array}$ https://doi.org/10.1016/j.jaap.2014.08.008.

[11] Aykut Nalbant, Özlem Ertek, and Ibrahim Okur, Producing $\mathrm{CuO}$ and $\mathrm{ZnO}$ composite thin films using the spin coating method on microscope glasses, Mater. Sci. Eng. B, 2013, 178, 368- 374 https://doi.org/10.1016/j.mseb.2013.01.010.

[12] Mustafa Amer Hassan, Studying the Effect of Doping in Some Physical Properties of Copper Oxide Thin Film, Engg. And tech. Journal, vol 30,2012

[13] Sachin H. Dhawankar, Avish K. Patil and B.M.Suryavanshi, Optical characterization of $\mathrm{CdO}$ thin films on dielectric substrate, International Journal of Innovative and Applied Research (2014), Volume 2, Issue (8): 67- 71

[14] Sachin H. Dhawankar, Avish K. Patil, B.M.Suryavanshi Optical Properties of $\mathrm{ZnO}$ Thin Film Deposited by Spray Pyrolysis applied physics letter,Vol_1, Issue_2, 2014

[15] Saturi Baco,Abdullah Chik,Fouziah Md. Yassin, study on optical properties of tin oxide thin film at different annealing temperature, journal of science and technology, 61-72

[16] F.Stern Elementry theory of the optical properties of solids, solid state physics, 15, P299-408, 1963.

[17] K.C.Lalithambika, K.Shanthakumari and S.Sriram, optical properties of $\mathrm{CdO}$ thin film deposited by chemical bath method, International Journal of ChemTech Research,Vol.6, No.5, pp 3071-3077, aug-Sept 2014. 